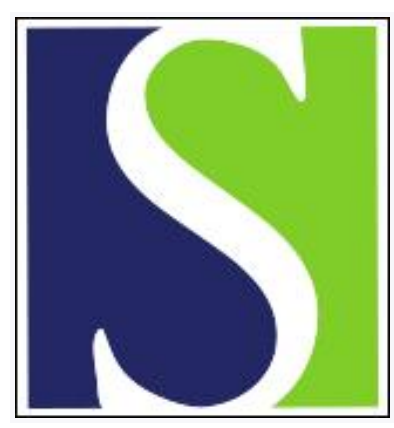

Scand J Work Environ Health 2000;26(2):106-111

https://doi.org/10.5271/sjweh.519

Issue date: Apr 2000

\title{
Cancer incidence among Norwegian airline pilots
}

by Haldorsen T, Reitan JB, Tveten U

The following articles refer to this text: 2001;27(3):161-213;

2003;29(2):94-99; 2010;36(2):163-179

Key terms: brain tumor; cosmic radiation; electromagnetic fields; epidemiology; leukemia; malignant melanoma; skin cancer

This article in PubMed: www.ncbi.nlm.nih.gov/pubmed/10817375

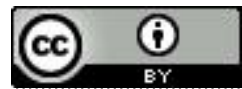




\title{
Cancer incidence among Norwegian airline pilots
}

\author{
by Tor Haldorsen, MSc, ${ }^{1}$ Jon B Reitan, MD, ${ }^{2}$ Ulf Tveten, $M S c^{3}$
}

\begin{abstract}
Haldorsen T, Reitan JB, Tveten U. Cancer incidence among Norwegian airline pilots. Scand J Work Environ Health 2000;26(2):106-111.
\end{abstract}

\begin{abstract}
Objectives In this retrospective cohort study, the cancer incidence of commercial pilots was studied to determine whether exposure at work has any influence on the incidence of cancer.

Methods The cohort was established from the files of the Civil Aviation Administration and included people who had valid licenses as commercial pilots between 1946 and 1994. Basic data about their flight careers were recorded, and exposure to cosmic radiation was estimated. The cohort was linked to the Cancer Register of Norway. The observed number of cases was compared with that expected based on national rates.

Results A group of 3701 male pilots was followed over 70560 person-years. There were 200 cases of cancer versus 188.8 expected, with a standardized incidence ratio (SIR) of 1.06 and a $95 \%$ confidence interval $(95 \% \mathrm{CI})$ of $0.92-1.22$. No significant decreased risk was found for any cancer site. Excess risks were found for malignant melanoma (22 cases SIR $1.8,95 \%$ CI 1.1 - 2.7) and nonmelanoma skin cancer (14 cases, SIR 2.4, 95\% CI 1.34.0). For malignant melanoma, there was a significant trend for the SIR by cumulative dose.

Conclusions For most cancer sites, the incidence among pilots did not deviate from that of the general population and could not be related to block hours of flight time or dose. It seems more likely that the excess risks of malignant melanoma and skin cancer are explained by factors related to life-style rather than by conditions at work.
\end{abstract}

Key terms brain tumor, cosmic radiation, electromagnetic fields, epidemiology, leukemia, malignant melanoma, skin cancer.

Airline pilots make up a specially selected occupational group. To enter this occupation, pilots have to show physical fitness and mental stability; in addition, during their career, they are under closer medical supervision than most other occupational groups. Their circadian rhythm is often disturbed by irregular workhours and, for some, travel through time zones. In the cockpit, they are exposed to low-frequency electromagnetic fields (1), an environmental factor that could be related to cancer (2). After the introduction of jet aircraft that had increasing cruising altitude, pilots have been exposed more to cosmic radiation (3). Ionizing radiation in higher doses is known, or suspected, to be a cause of several types of cancer (4), and international recommendations regulate such exposure during work (5). There is discussion about how to check that the exposure of pilots and cabin crew is within acceptable limits and how to impose regulations $(6,7)$.

Previous studies of cause-specific mortality and cancer incidence among pilots include proportional mortality studies $(8,9)$, cohort studies $(10-13)$, and nested case-referent studies of brain tumors $(14,15)$. An excess mortality from brain tumors has been found in some of these studies $(8,9,11)$, and an excess incidence of brain tumors was found in 1 of the cohort studies (11). There have also been reports of excess incidence for all sites combined, testis and urinary bladder (13), and cancer of the prostate and acute myeloid leukemia (12). An excess risk of breast cancer has been observed among female cabin attendants (16).

The aim of this work was to study cancer incidence among Norwegian commercial pilots, with an emphasis on cancer sites that are related to known workplace exposures.

\section{Materials and methods}

The Civil Aviation Administration (CAA) authorizes commercial pilots in Norway. The cohort was put together from information in the files at the Personnel

1 The Cancer Registry of Norway, Oslo, Norway.

2 Norwegian Radiation Protection Authority, Østerås, Norway.

3 Institute of Energy Technology, Kjeller, Norway.

Reprint requests to: Tor Haldorsen, The Cancer Registry of Norway, Montebello, N-0310 Oslo, Norway. [E-mail: th@kreftreg.no] 
Licensing Section and Aviation Medical Section of the CAA; it includes all pilots who had a valid license between January 1946 and February 1994. Pilots under 40 years of age renew their license every year, and older pilots renew their license every 6 months. Helicopter pilots and flight engineers were included, but pilots of foreign nationality, who were not inhabitants of Norway, were not included.

The following information was extracted from the files at the Personnel Licensing Section: name, date of birth, type of license, company (if available), date of license for specific aircraft, date of renewals for license, and cumulative block hours at renewals. (Block hours are the flight hours measured between leaving the departure gate and arrival at the destination gate.) From the Aviation Medical Section, we also obtained results on selfreported smoking habits recorded at the time of a medical examination and supplementary information about aircraft and block hours.

Altogether, 3815 pilots were included in the cohort; 63 female pilots were excluded from this analysis because of the small number.

Since 1964 all inhabitants of Norway have a unique identification number, and these numbers were searched for persons in the cohort. Nine pilots who had been active after 1964 could not be identified and were excluded.

The date of death or emigration was found by linkage to the population register of Norway through the identification number. Nineteen pilots had their first license after emigration and were excluded. Before 1965, the cohort was linked to the death register by name and date of birth. Those with no identification number, who had no contact with the CAA after 1964, and whose names were not in the death register were assumed to have emigrated after the last date of contact.

Flying activities were measured by block hours. These hours are registered at the CAA at the time of license renewal; the information is extracted from the logbooks of the pilots or confirmed by the airline companies. Separate block hours are given for each type of license (ie, fixed wing, flight engineer or helicopter). $\mathrm{Cu}$ mulative block hours include the documented block hours before the date of the first license. Block hours for the time after first license were recomputed by calendar years, and hours were added from the 3 types of licenses.

Doses of cumulative cosmic radiation during flights from the first date of the license were estimated annually using a special procedure. These details have been reported elsewhere $(17,18)$. In essence, each type of aircraft was assigned a dose rate per block hour in microsieverts for 5-year periods. For aircrafts of the Scandinavian Airline System (SAS), there was a mixture of routes flown by the planes according to the SAS timetables. The Pilots Association was consulted about the flight profiles of these routes, and a dose rate for each route was calculated using a computer program (CARI$3 N$ ) from the US Federal Aviation Administration. The average dose rate for a plane was found by weighting the dose rate from separate flights according to the total usage of the plane. For the planes not used by the SAS, the Pilots Association suggested representative flights and the estimated dose rate of these flights was used. The planes were divided into 39 groups, and the dose rates for these ranged from 0.03 to $4.00 \mu \mathrm{Sv} / \mathrm{h}$.

The dose for each year was found by multiplying the block hours by the dose rate for the plane flown by the pilot. Usually, pilots are authorized to fly several types of planes; for the estimation procedure planes with a later date of license were chosen. Where there were several planes with the same date of license, we chose the plane with the higher dose rate. For flight engineers, $20.9 \%$ of the licenses lacked information about the plane, and they were therefore assigned to the most common plane among this group.

There was no information on tobacco use for $25.9 \%$ of the pilots; for the others, there was an average of 5.8 observations of tobacco use during their careers.

Since 1953, the Cancer Registry of Norway has collected data on incident cases of cancer in the total population. The registration system is built on multiple reporting from pathological laboratories and hospital departments; there is compulsory reporting from physicians. The coding of cancers is based on a modified version of the International Classification of Diseases, 7 th revision (ICD-7) (19).

The cohort was linked to the Cancer Register by either the identification number or name and date of birth. The follow-up on cancer started on the date of the first license or on 1 January 1953, whichever was later, and ended at emigration, at death, or on 31 December 1996.

In the cohort, 13 had died and 10 had emigrated before 1953; this left 3701 for the follow-up on cancer incidence.

The observed number of cases was compared with the expected number of cases, and standardized incidence ratios (SIR) were computed as the ratio between the observed and expected. The expected number of cases was computed by multiplying the person-years in the cohort by national rates for 5-year periods and 5-year age groups. The $95 \%$ confidence intervals $(95 \% \mathrm{CI}$ ) of the SIR values were computed by assuming that the observed number of cases followed the Poisson distribution. Observed versus expected values in different studies were compared using an exact binomial test (20). Trends for the SIR were examined by categorization of the exposure variables. Trend tests were performed by assigning average scores to the categories (20). The software package EPICURE was used in the analysis (21). 


\section{Results}

A cohort of 3701 male pilots was eligible for the followup of cancer incidence. During the follow-up, 353 pilots died and 327 emigrated. The number of person-years was 70560 , and about $15 \%$ of the person-years were attributed to pilots aged 55 years and older.

The number of active pilots and their exposure in terms of annual block hours and dose for 4 distinct years during the follow-up are reported in table 1. There has been a steady increase in the number of active pilots by time, but a small decrease in their average block hours. In 1958, before the jet age, no pilot had an estimated dose

Table 1. Yearly block hours and dose for active pilots.

\begin{tabular}{lccccc}
\hline Year & $\begin{array}{c}\text { Number of } \\
\text { pilots }\end{array}$ & $\begin{array}{r}\text { Mean } \\
\text { block } \\
\text { hours }\end{array}$ & $\begin{array}{c}\text { Number of } \\
\text { pilots above } \\
500 \text { block } \\
\text { hours }\end{array}$ & $\begin{array}{c}\text { Mean } \\
\text { dose } \\
(\mathrm{mSv})\end{array}$ & $\begin{array}{c}\text { Number of } \\
\text { pilots } \\
\text { above } \\
1 \mathrm{mSv}\end{array}$ \\
\hline 1958 & 472 & 495 & 259 & 0.12 & - \\
1968 & 904 & 434 & 363 & 0.33 & 116 \\
1978 & 1167 & 471 & 483 & 0.47 & 233 \\
1988 & 1778 & 397 & 554 & 0.45 & 333 \\
\hline
\end{tabular}

Table 2.0bserved number of cases $(0)$, standardized incidence ratios (SIR) and $95 \%$ confidence intervals $(95 \% \mathrm{Cl})$ for 3701 male pilots.

\begin{tabular}{|c|c|c|c|}
\hline Cancer site & 0 & SIR & $95 \% \mathrm{Cl}$ \\
\hline All sites $(140-204)$ & 200 & 1.06 & $0.92-1.22$ \\
\hline Upper respiratory tract $(141,143-8,161)$ & 8 & 1.1 & $0.5-2.3$ \\
\hline Esophagus (150) & 3 & 1.5 & $0.3-4.3$ \\
\hline Stomach (151) & 9 & 0.9 & $0.4-1.7$ \\
\hline Colon (153) & 16 & 1.1 & $0.6-1.7$ \\
\hline Rectum (154) & 9 & 0.9 & $0.4-1.7$ \\
\hline Liver (155.0) & - & 0.0 & $0.0-3.1$ \\
\hline Pancreas (157) & 4 & 0.7 & $0.2-1.9$ \\
\hline Lung (162) & 25 & 1.0 & $0.6-1.5$ \\
\hline Breast $(170)$ & - & 0.0 & $0.0-13.0$ \\
\hline Prostate (177) & 25 & 1.0 & $0.7-1.5$ \\
\hline Testis (178) & 11 & 1.5 & $0.7-2.6$ \\
\hline Kidney (180) & 4 & 0.5 & $0.1-1.4$ \\
\hline Bladder (181) & 11 & 0.8 & $0.4-1.5$ \\
\hline Malignant melanoma (190) & 22 & 1.8 & $1.1-2.7$ \\
\hline Nonmelanoma skin $(191)^{\mathrm{b}}$ & 14 & 2.4 & $1.3-4.0$ \\
\hline Brain, nervous system (193) & 9 & 1.1 & $0.5-2.1$ \\
\hline Thyroid (194) & 2 & 1.3 & $0.2-4.7$ \\
\hline Bone (196) & - & 0.0 & $0.0-6.3$ \\
\hline Soft tissue (197) & - & 0.0 & $0.0-3.1$ \\
\hline Hodgkin's disease (201) & 3 & 1.4 & $0.3-4.1$ \\
\hline Non-Hodgkin's Jymphoma $(200,202)$ & 7 & 1.0 & $0.4-2.0$ \\
\hline Leukemia (204) & 2 & 0.5 & $0.1-1.7$ \\
\hline $\begin{array}{l}\text { Leukemia excluding chronic } \\
\text { lymphoid leukemia (204) }\end{array}$ & 1 & 0.3 & $0.0-1.7$ \\
\hline Multiple myeloma (203) & 2 & 0.7 & $0.1-2.6$ \\
\hline Unspecified (199) & 7 & 1.1 & $0.4-2.3$ \\
\hline Other sites (Rest 140-204) & 7 & 0.9 & $0.4-1.9$ \\
\hline
\end{tabular}

a Codes of the International Classification of Diseases (7th revision) in parentheses.

- Basal-cell carcinoma not included. above $1 \mathrm{mSv}$. With time, there has been an increase in the average dose. As expected, there has been an increasing number of pilots with estimated annual doses of $>1$ mSv over time.

Smoking habits among active pilots were recorded and compared with those expected, computed from the general population using age-specific proportions (22) and the age distribution of pilots. The proportion of current smokers among the pilots versus the expected were 72 versus 74 for 1955,63 versus 65 for 1965,52 versus 54 for 1975,41 versus 45 for 1985 , and 32 versus 38 for 1993. For each year, the number of smokers among the pilots was based on the last reported status.

During the follow-up, 200 cases of cancer were observed, and the results for specific cancer sites are given in table 2 . For only 2 of the sites was the SIR value significantly different from 1.0. Elevated risks were seen for both malignant melanoma (SIR 1.8) and nonmelanoma skin cancer (SIR 2.4) (excluding basal-cell carcinomas).

Of the 9 brain tumors observed, 2 were astrocytomas and 3 were glioblastomas; the expected number for these subtypes was 1.1 and 2.6, respectively. One of the 2 cases of thyroid cancers was of the papillary type. Both cases of leukemia were chronic: 1 lymphoid and 1 myeloid.

For cancer sites with more than 10 cases and selected groups, the trends for the SIR by block hours and dose are given in tables 3 and 4 . For cancer of the colon, lung, testis, prostate, and bladder, there was no apparent trend for the SIR with respect to the exposure variables. For malignant melanoma, there was an increasing trend for the SIR by dose, but it was less apparent for block hours. For all cancers combined, there were traces of trends with the exposure variables, but they disappeared when malignant melanoma and nonmelanoma skin cancer were excluded from the cases. Brain tumors and leukemia combined did not exhibit any trend for the SIR by block hours. The 3 cases of thyroid cancer and leukemia, excluding chronic lymphoid leukemia, were found in the lower categories by dose.

\section{Discussion}

Norwegian airline pilots experienced an incidence of cancer close to that of the average population with 2 exceptions: they had an excess risk for malignant melanoma and for nonmelanoma skin cancer (excluding basal cell carcinomas). Elevated SIR values for these types of cancer have also been found in previous studies of pilots. In a study of 913 pilots from Canadian Airlines International, the SIR values were 1.96 and 1.59 (11). In a later and larger study from Air Canada, the SIR for malignant melanoma was 1.52 , whereas nonmelanoma skin cancer was not reported (12). In a study of pilots in the US Air 
Force (USAF), the SIR values were 1.50 and 1.45 , in a comparison with the general population (13). Excess deaths of melanoma have been found in proportional mortality studies $(8,9)$.

Solar radiation is a major risk factor for both these types of cancer. According to measurements, pilots are exposed to negligible doses of ultraviolet radiation in the cockpit (23). For both these cancer sites, we compared the body distribution of the cases among the pilots with

Table 3. Observed number of cases $(0)$, standardized incidence ratios (SIR) and 95\% confidence intervals $(95 \% \mathrm{Cl}$ ) for selected sites by cumulative block hours.

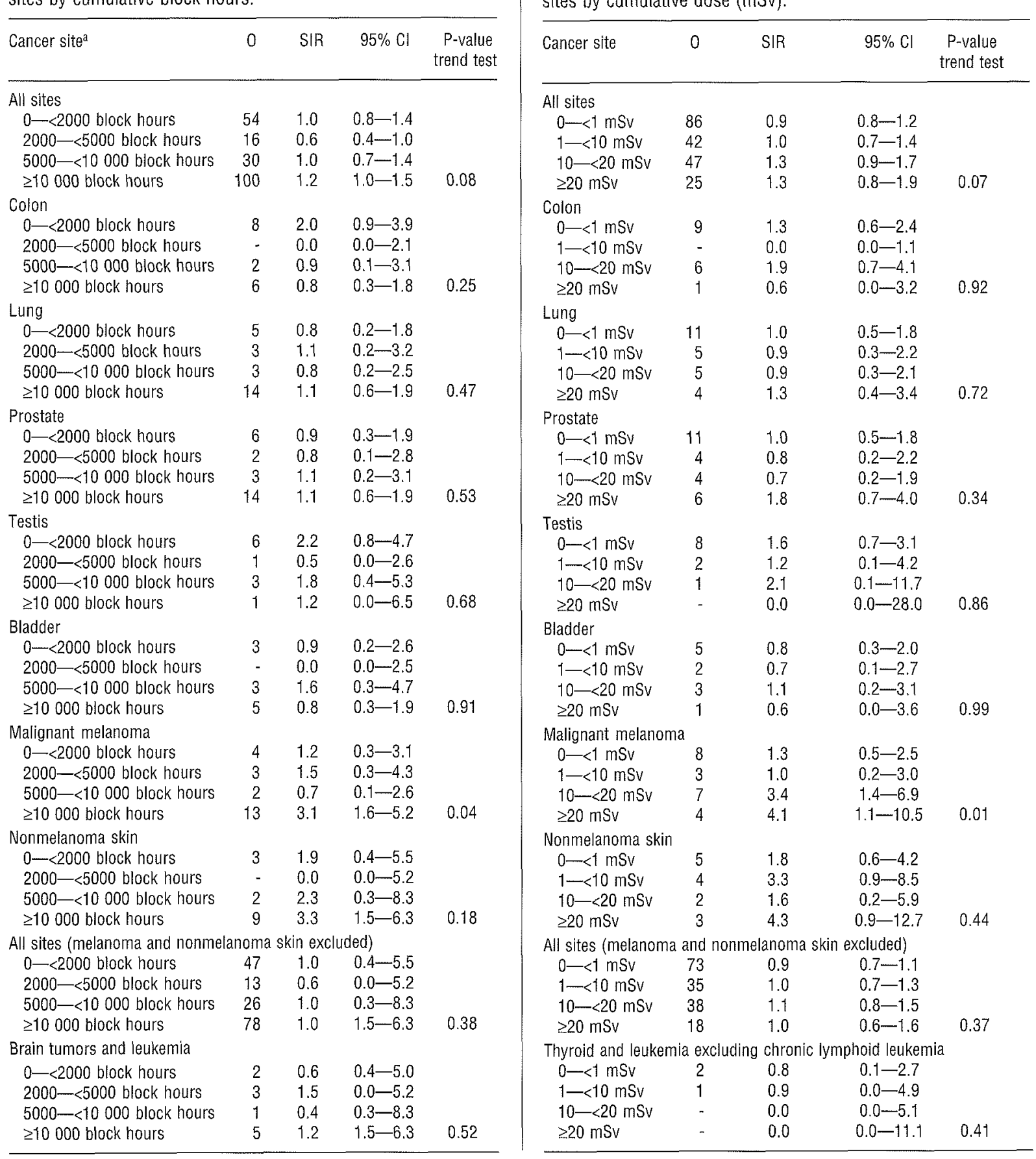

Scand J Work Environ Health 2000, vol 26, no 2 that of the total population. For the pilots, these cancers were not found more often on the head, neck or hands (ie, the parts of the body that might be exposed in the cockpit). In a census-based study of cancer incidence in occupational groups in the Nordic countries, a high incidence of these cancers was found in several occupational groups in association with upper social class (24).

We observed an increasing trend for the SIR value with dose for malignant melanoma (table 4). Ionizing

Table 4. Observed number of cases (0), standardized incidence ratios (SIR) and $95 \%$ confidence intervals $(95 \% \mathrm{Cl})$ for selected sites by cumulative dose (mSv). 
radiation is a known risk factor for nonmelanoma skin cancer, but it has been related to malignant melanoma to a less degree. The dose was deemed to be an indicator of ionizing radiation, but we must be aware that, as the higher dose rates occurred in planes used on medium-distance European and long-range intercontinental flights, it may also reflect opportunities for sunbathing in leisure time. So far, it seems more likely that the excess risk of melanoma and nonmelanoma skin cancer may be explained by social class and leisure-time activities rather than by conditions at the workplace.

The exposure to cosmic radiation is the best documented exposure to workplace carcinogens for pilots. Thyroid cancer and leukemia excluding chronic lymphoid leukemia are cancer sites that are more often related to ionizing radiation. We observed 2 cases, as against 1.5 expected, of thyroid cancer and 1 case, as against 3.3 expected, of leukemia excluding chronic lymphoid leukemia. These cases were not found in the upper dose categories (table 4). In the study of USAF pilots, there was no excess risk of leukemia: 13 cases versus 14.6 expected (13); in the study of Air Canada pilots, however, there were 7 cases of leukemia excluding chronic lymphoid leukemia versus 3.72 expected (12). Small numbers prevent decisive comments, because the results from all 3 studies cannot be said to be incompatible.

The knowledge about some exposure to ionizing radiation does raise some concern with regard to cancer incidence at almost all sites for pilots. The incidence of all sites was not significantly different from that expected. For all sites combined, there may be a slight trend with dose. As a result of the excess risk and the special pattern for melanoma and other skin cancer among pilots, we also investigated the trend by dose when excluding these 2 sites. For the remaining sites, there is little evidence of a trend by dose, but this result should be interpreted with care because of the limited size of the study. The mean dose weighted for person-years in the upper category was $24.7 \mathrm{mSv}$. To have an $80 \%$ power in detecting a significant trend for dose, the relative risk for this category should be almost 2 . In a large study of nuclear industry workers, a nonsignificant negative trend by dose was found for all cancers except leukemia (25).

Apart from ionizing radiation, pilots are exposed to electromagnetic fields, but the effect of this exposure on cancer incidence is not clear. Most studies of this exposure seek to unravel the connection with leukemia and brain tumors. Among pilots, excess deaths from tumors of the brain or central nervous system (CNS) were found in previous proportional mortality studies $(8,9)$. Elevated risks for this site have also been found in some cohort studies $(11,12)$, but others indicate a decreased risk (13). Our study with 9 cases, against the 8.0 expected, represents an intermediate result between 7 versus 4.57 in the
Air Canada study (12) and 13 versus 18.3 in the USAF study (13). The results for leukemia are equally diverse. We do not know how exposure to electromagnetic fields varies according to aircraft, and block hours have been used as an indicator. The combined results for brain tumors and leukemia do not indicate any trend by block hours (table 3 ), although with only 11 cases we have limited power to detect small elevations in risk, such as that indicated for brain tumors in a case-referent study in the US Air Force (15).

Former studies of pilots have indicated deviations from the cancer incidence of the general population without referring them to specific exposures. Proportional mortality studies $(8,9)$ have suggested an increased risk for colon cancer among pilots. Our study, like a later cohort study (12), does not corroborate this finding. Nor did we observe any increased risk for rectal cancer in the Norwegian cohort.

In the Air Canada study, a decreased risk for all cancers was found (12). It was mainly caused by a decreased risk for smoking-related cancers such as lung and bladder cancer. In our material, the pilots did not experience a decreased risk for these cancers or for cancers of the upper respiratory and gastric tract, which are also smoking-related. We collected information on smoking habits for the pilots. In Norway, it is only in later years that the proportion of current smokers has been noticeably less among pilots than among the general population.

An increased risk for cancer of the prostate was found in the Air Canada study, and it was suggested that routine use of a digital rectal examination was part of the explanation (12). The same procedure is used for pilots over 50 years of age in Norway, but it does not seem to have increased the incidence of prostate cancer among pilots over that of the general population.

In our study, we used 2 indicators of exposure, cumulative block hours and cumulative estimated dose. Block hours closely measure the time that pilots have been at work in the cockpit. It is a quantity that is important to pilots, their companies, and the licensing authorities, and we consider the registration to be of high quality. The doses were indirectly estimated by annual information of block hours and the average use of different airplanes. The actual doses to pilots in the same type of plane will depend on the routes flown, and we have not estimated this individual variation. On the other hand, the range of cruising altitude for the planes allowed us to assign a 100-fold increase in the dose rate to the higher planes relative to the lower ones. The individual variation may be small when compared with the variation between planes.

The cohort included some people who have had a short career as a commercial pilot. We checked whether this occurrence influenced the results by separate computations of observed and expected results for the 
person-time both before and after 3 years of active flying, but we could not find any "short-time worker" effect.

There is a steep increase in cancer incidence by age, and, even if we included active pilots back to 1946, most of the person-years involved during the follow-up had been gained at a relatively young age. Specific incidence patterns may emerge when more pilots are observed after the age of 55 years.

Cancer incidence among Norwegian pilots exhibited few deviations from that of the general population. We did not reveal cancer risks that could be definitely attributed to the workplace environment. A longer follow-up of this study cohort and studies of other cohorts of pilots will give more precise information on the cancer risks of pilots.

\section{Acknowledgments}

This study was supported by grants from the Norwegian Research Council.

We are grateful to the staff of the Personnel Licensing Section (CAA), Chief Medical Officer Per Arva, and his staff at the Aviation Medical Section (CAA), and members of the Pilots Association for their help and advice. We thank Per Irgens, Lindis B Østlie, and Jan I Martinsen for their data entry and the last-mentioned for editing the data and running the analyses.

\section{References}

1. Nicholas JS, Lackland DT, Butler GC, Mohr LC Jr, Dunbar JB, Kaune WT, et al. Cosmic radiation and magnetic field exposure to airline flight crew. Am J Ind Med 1998;34:574_ 80.

2. Feychting M, Forssen U, Floderus B. Occupational and residential magnetic field exposure and leukemia and central nervous system tumors. Epidemiology 1997;8:384-9.

3. Friedberg W, Faulkner DN, Snyder L, Darden EB Jr, O'Brien $\mathrm{K}$. Galactic cosmic radiation exposure and associated health risks for air carrier crewmembers. Aviat Space Environ Med 1989;60:1104-8.

4. Boice JD, Jr, Land CE, Preston DL. Ionizing radiation. In: Schottenfeld D, Fraumeni JF Jr, editors. Cancer epidemiology and prevention. 2nd ed. New York (NY): Oxford University Press, 1996:319-54.

5. International Commission on Radiological Protection (ICRP). 1990 Recommendations of the International Commission on Radiological Protection. Oxford: Pergamon Press, 1991. Annals of the ICRP 21(1-3). ICRP publication 60 .

6. Wilson OJ, Young BF, Richardson CK. Cosmic radiation doses received by Australian commercial flight crews and the implications of ICRP 60. Health Phys 1994;66:493-502.
7. European Commision. Council directive 96/29/Euratom. Off J Eur Communities 1996;39(L159):1-18.

8. Irvine D, Davies DM. The mortality of British Airways pilots, 1966-1989: a proportional mortality study. Aviat Space Environ Med 1992;63:276—9.

9. Salisbury DA, Band PR, Threlfall WJ, Gallagher RP. Mortality among British Columbia pilots. Aviat Space Environ Med 1991;62:351-2.

10. Kaji M, Tango T, Asukata I, Tajima N, Yamamoto K, Yamamoto $\mathrm{Y}$, et al. Mortality experience of cockpit crewmembers from Japan Airlines. Aviat Space Environ Med 1993;64:748-50.

11. Band PR, Spinelli JJ, Ng VT, Moody J, Gallagher RP. Mortality and cancer incidence in a cohort of commercial airline pilots. Aviat Space Environ Med 1990;61:299-302.

12. Band PR, Le ND, Fang R, Deschamps M, Coldman AJ, Gallagher RP, et al. Cohort study of Air Canada pilots: mortality, cancer incidence, and leukemia risk. Am J Epidemiol 1996;143:137-43.

13. Grayson JK, Lyons TJ. Cancer incidence in United States Air Force aircrew, 1975-89. Aviat Space Environ Med 1996;67:101-4.

14. Grayson JK, Lyons TJ. Brain cancer, flying, and socioeconomic status: a nested case-control study of USAF aircrew. Aviat Space Environ Med 1996;67:1152-4.

15. Grayson JK. Radiation exposure, socioeconomic status, and brain tumor risk in the US Air Force: a nested case-control study, Am J Epidemiol 1996;143:480 - 6.

16. Pukkala E, Auvinen A, Wahlberg G. Incidence of cancer among Finnish airline cabin attendants, 1967-92. BMJ 1995;311:649-52.

17. Tveten U. Cosmic radiation and airline pilots. Exposure patterns of Norwegian SAS-pilots 1960 to 1994. Kjeller (Norway): Institute for Energy Technology, 1997. Institute for Energy Technology IFE/KR/E-96/008

18. Tveten U. Cosmic radiation and airline pilots: exposure patterns of Norwegian pilots flying aircraft not used by SAS. Kjeller (Norway): Institute for Energy Technology, 1997. Institute for Energy Technology IFE/KR/E-97/003.

19. World Health Organization (WHO). International classification of diseases, seventh revision. Geneva: WHO, 1957.

20. Breslow NE, Day NE. Statistical methods in cancer research; vol II (The design and analysis of cohort studies). Lyon: International Agency for Research on Cancer (IARC), 1987. IARC scientific publications, no 82.

21. Preston DL, Lubin JH, Pierce DA, McConney ME. EPICURE: user's guide. Seattle (WA): Hirosoft International Corporation, 1993.

22. Rønneberg A, Lund KE, Hafstad A. Lifetime smoking habits among Norwegian men and women born between 1890 and 1974. Int J Epidemiol 1994;23:267-76.

23. Diffey BL, Roscoe AH. Exposure to solar ultraviolet radiation in flight. Aviat Space Environ Med 1990;61:1032-5.

24. Andersen A, Barlow L, Engeland A, Kjærheim K, Lynge E, Pukkala E. Occupational cancer in the Nordic countries. Scand J Work Environ Health 1999;25 suppl 2:1-116.

25. IARC Study Group on Cancer Risk among Nuclear Industry Workers. Direct estimates of cancer mortality due to low doses of ionising radiation: an international study. Lancet 1994;344:1039- 43 .

Received for publication: 21 April 1999 